Soccer \& Society

\title{
Organizing the World Cup in an historical perspective: new challenges and topics
}

Philippe Vonnard , Clément Astruc , Lorenzo Jalabert D’Amado \& Nicola Sbetti

To cite this article: Philippe Vonnard, Clément Astruc , Lorenzo Jalabert D'Amado \& Nicola Sbetti (2020) Organizing the World Cup in an historical perspective: new challenges and topics, Soccer \& Society, 21:8, 841-847, DOI: 10.1080/14660970.2020.1793630

To link to this article: https://doi.org/10.1080/14660970.2020.1793630

册 Published online: 29 Oct 2020.

Submit your article to this journal $\llbracket$

Q View related articles $\widetilde{ }$

View Crossmark data 


\title{
Organizing the World Cup in an historical perspective: new challenges and topics
}

\author{
Philippe Vonnard ${ }^{\mathrm{a}}$, Clément Astruc ${ }^{\mathrm{b}}$, Lorenzo Jalabert D’Amado ${ }^{\mathrm{b}}$ and Nicola Sbetti ${ }^{\mathrm{c}}$
}

anstitute of Sport Sciences, University of Lausanne, Lausanne, Switzerland; bUniversity Sorbonne Nouvelle University, CNRS CREDA, Paris, France; 'Department for Life Quality Studies, University of Bologna, Bologna, Italy

The FIFA men's World Cup is undoubtedly a 'mega-event.' Alongside the Summer Olympic Games, it is indeed the most-watched sporting event on the planet. According to its organizer, the Fédération Internationale de Football Association (FIFA), more than a billion people watched the 2018 final on television, and the cumulative audience for the competition held in Russia was more than three billion people. ${ }^{2}$ Throughout its history, the tournament has played a major role in the internationalization of football. The process, however, started during the late nineteenth century and was greatly reinforced during the inter-War period with the birth of the men's World Cup. By the end of the Second World War, this movement continued to strengthen under the dual influence of decolonization and the ever growing broadcasting and commercialization of the game (especially from the 1960s-1970s). ${ }^{3}$

The tournament only gradually attained the global scope that it currently enjoys. In fact, from the first edition held in Uruguay (1930) up to the World Cup organized in Mexico (1970), the competition almost exclusively included European and South American countries. Since then, the growing importance of Africa and Asia within FIFA has challenged the geopolitics of football. This process of globalization was supported by two successive FIFA presidents, the Brazilian João Havelange (1974-1998) and the Swiss Joseph 'Sepp' Blatter (1998-2016). Nonetheless, Europe and South America have continued to dominate the competition on the basis of results.

\section{Men's World Cup: a brief state of the art}

In the past few decades, scholars have approached the history of the men's World Cup from diverse perspectives. One of the most common approaches so far has been to focus on the political implications of the event. Historians who have taken on this task have successfully highlighted the role played by football teams taking part in the tournament as strong representatives of national identity. They have also showcased the overall tendency to instrumentalize the event at the international level - by authoritarian regimes, but also by democracies - as instruments of 'soft power' and/or 'public diplomacy'. Histoire politique des Coupes $d u$ monde, co-written by Paul Dietschy, Yvan Gastaut and Stéphane Mourlane in 2006, for example, deals with some of these aspects of research. ${ }^{4}$ More recently, Riccardo Brizzi and Nicola Sbetti have also published a political history of the event, mainly based on the various works published since the turn of the twentieth century. ${ }^{5}$ The close relationship between the men's World Cup and the building of national discourses has been highlighted for several countries as well. Ronaldo Helal and Alvaro do Cabo examined this phenomenon in a long-term perspective in a volume published in $2014{ }^{6}$ Lívia Gonçalves Magalhães has offered a comparative study between the Mexico 1970 (won by Brazil) and Argentina 1978 (won by the host country) men's World Cup editions, in order to analyse the 
meaning and implications of an international football victory for countries under authoritarian rule. ${ }^{7}$ Political studies of the men's World Cup have also been conducted in one-off studies focusing on a specific edition. Among others, we can highlight Kay Schiller's work on the 1974 tournament held in West Germany or Juan Antonio Simón Sanjurjo's book on the 1982 Spanish Mundial. ${ }^{8}$

In the past decade, the field of men's World Cup history has been shifting towards the inclusion of broader topics alongside the traditional political approach to the subject. Such newer studies deal in particular with the economic, media and cultural implications of the event. ${ }^{9}$ These new approaches have given us a better understanding of the overall transformation of the event and led to the publication of comprehensive histories of it. We could for instance refer to the consequential 2006 international symposium organized by Alfred $\mathrm{Wahl}^{10}$ - a pioneer in the history of football in France - and the synthesis he produced in 2013 offering a comprehensive theme-based interpretation of the tournament. ${ }^{11}$ Then, in 2014, Stefan Rinke and Kay Schiller provided a rich series of case studies written by specialists of various nationalities covering the entire 1930-2010 period. $^{12}$

As shown by this brief - and by no means exhaustive - state of the art, the FIFA men's World Cup is far from being virgin field of research. Indeed, enlargement of the scope of the subject means that several aspects of the tournament are yet to be explored. Alfred Wahl, for instance, has identified some 'blind spots' - such as the link between the competition and the tourism industry, which has evolved considerably over time both in its scope and in its treatment by the host country $^{13}$ - and attempted to lay the groundwork for their exploration. This requires careful consideration of new archival sources and hitherto untapped materials.

Among such unexplored subjects requiring attention, one crucial area concerns the organizational aspects of the tournament - in particular the study of its promoters, its bidding process and the event's heritage. The men's World Cup history lags far behind the research on the history of Olympic Games in this regard. The organization and legacies of both Summer and Winter Olympic Games, for example, have been studied in much greater breadth by several historians. ${ }^{14}$

\section{Organizing the World Cup}

Based on these observations, this special issue offers a series of case studies discussing the cultural, economic, political and social dimensions of the organization of the event. It not only considers the successful and effective men's World Cup organizational processes, but also takes into consideration one of its somewhat neglected aspects: failed bids. The papers of this volume were presented at an international congress held in Paris in June 2018 (at the beginning of the last men's World Cup). Funded by various institutions, ${ }^{15}$ this scientific event brought together around twenty researchers from ten different countries.

The special issue has three main, complementary aims: first, the desire to enlarge World Cup history through a better understanding of the editions organized in the Americas. As a matter of fact - and for obvious research scale reasons - the event's academic history is still predominantly centred on the tournaments held in Europe. In an attempt to attenuate this historiographical trend, this special issue has sought to showcase editions of the tournament held in the Americas. A second aim, at a methodological level, has been to try to have the papers rely on cross-referenced archives sometimes unpublished or little-used - produced by national and international institutions and by stakeholders from both the political and sports fields. In this regard, the contrasts that can be observed in terms of documentation between the different articles underline how the quantity and nature of the first-hand sources available vary greatly from one area to another and from one country to another. This material asymmetry is a major obstacle when trying to carry out comparative studies between editions. The third aim is to keep enlarging the scope of the men's World Cup history by exploring hitherto unaddressed topics. Thus, and in addition to the relatively 'traditional' studies on State investment in the event for domestic or international political issues, 
some papers deal with the construction of the memory and heritage of men's World Cups as well as with failed bids.

As far as the organizational aspect of the tournament is concerned, three distinct but interconnected time frames can be identified: before the event (the moment when the country decides to send an application to FIFA); during the event (the actions that make it possible to set up the event, including the period when the competition is actually held); and after the event (which consists of studying the effects of the organization of the tournament on the host country, whether in terms of infrastructure, football practice or even collective memory). The papers included in this special issue concentrate their efforts on these different time frames.

\section{Content of the special issue}

The special issue is divided in three parts, each of which comprises three papers. The first part deals with three Latin American editions of the men's World Cup, studied from a political and diplomatic perspective. Lorenzo Jalabert D'Amado opens the floor with a reassessment of the genesis and pathway of Uruguay's bid for the inaugural men's World Cup of 1930. In addition to exploring Uruguayan efforts to host the event, this paper also highlights the early rift - and its depth - that appeared between European and Latin American football at that time. This division would leave a lasting mark on the history of the competition and the geopolitics of football in the following decades.

Twenty years later, the men's World Cup returned to South America, this time to Brazil. This event is the focus of Clément Astruc's article in which he investigates the various challenges faced by the organizers of this first post-Second World War edition (notably the construction of the world's largest stadium and the promotion of the tournament abroad). He takes a careful look at the role played by the various Brazilian public authorities in the event and questions in particular the involvement of Itamaraty - the Ministry of Foreign Affairs - and its diplomats. He also analyzes the representations of Brazil and Brazilian football conveyed by the European journalists dispatched to South America to cover the competition.

With Axel Elias Jimenez's piece, we move ahead another twenty years to the 1970 Mexican tournament. Jimenez shows that although the men's World Cup was held in the aftermath of the 1968 Mexico City Olympics, it cannot be placed at the same level. Elias describes how, in addition to less significant State investment in the men's World Cup compared to the Summer Olympics, the issues at stake and the respective objectives of these two events were radically distinct despite their proximity in time.

The two first articles show that, both when it was created in 1930 and held in 1950, the event enjoyed strong commitment of the Uruguayan and Brazilian public authorities and aroused huge national enthusiasm, often considered surprising and even disproportionate by contemporary European players, leaders and journalists. Although the difficulties encountered in bringing together 16 teams (particularly from the 'Old World') were major factors in the organization of these two editions, their success - both in terms of spectatorship and finance - at two decisive moments in FIFA's history significantly contributed to the event's future growth and popularity. When Mexico hosted the event, its relevance was no longer an issue and its success was undiminished, especially as it had in the meantime become a television spectacle and, by the same token, a commercial venture.

The papers of the second part focus on the issue of the various men's World Cup memories. The fourth article is a joint production of Nicola Sbetti and Daniele Serapiglia. It deals with a 'blind spot' in the nonetheless abundant research on the memory of the 1934 men's World Cup organized under the fascist regime of Benito Mussolini. The two authors analyse how the memory of the organization, marked by the victory of the Italian team, evolved during the so-called first Italian republic (1946-1994). Particular attention is given to the 'de-fascisation' of the 1934 victory in 
society, especially on the eve of the 1990 men's World Cup, organized in Italy and played in several stadiums that had been used during the 1934 tournament.

A different continent, but a similar question: what memory remains of the 1978 men's World Cup? Lívia Gonçalves Magalhães examines this thorny question in her article, looking back over the 40 years of memory that Argentine society has gradually built up around the event. Magalhães' analysis reveals that the memory of this men's World Cup has evolved over different periods: it has been torn between the euphoria of the first - and much-awaited - Albiceleste victory on the one hand and the criticism of its exploitation by the dictatorship then in place on the other. The author highlights the concordance between this evolution in memory and the political changes Argentina has undergone over the last four decades, with each government revisiting this landmark event of the nation's past.

The second part concludes with a piece written by Juan Antonio Simón Sanjurjo about the 1982 men's World Cup in Spain. Here the cultural memory is more ambiguous, as the event took place in a Spain that had effected its democratic transition (Franco died in 1975, and his regime was officially abolished in 1978). However, the remnants of Franco's regime were still present in the country. Furthermore, the organization of this tournament was also an economic issue, as it was meant to help solidify Spain's position as a tourist destination.

These three articles - which should be understood as primarily exploratory in nature - highlight the importance of the World Cup in a country's collective memory. As objects in perpetual evolution, the memory constructions of these sporting events, which have marked their eras and societies, constitute a particularly promising field of research for future generations of sports historians (and this is true for not only the men's but also the Women's World Cup).

The authors of the third part venture out on an area that is still virtually unexplored in the study of men's World Cups: the failing bids. These failed attempts are by nature more difficult to document than a successful bid, but they are nonetheless essential to better understand what makes a bid successful.

Following this approach, Lucie Hémeury has focussed on the failure of Argentina's bid for the 1962 men's World Cup. While the Peronist government positioned its country at the forefront of international sporting exchanges (in particular by having organized the Pan-American Games in Buenos Aires in 1951 and having floated the idea of organizing the Summer Olympic Games), the change of regime in 1955 obstructed this policy. This shift impacted Argentina's bid and consequently helped a smaller country with a lesser footballing reputation, Chile, to win the race for the event organization.

George Kioussis discusses another men's World Cup in the 'New World', covering the United States' desire to host the 1986 tournament by replacing Colombia (which was forced to withdraw in 1983 for domestic political reasons). Drawing on rich archival material (notably personal papers from Henry Kissinger), Kioussis describes in detail the actions - or rather the US lobbying - to convince the FIFA executive committee to award the event to the country. Despite these actions, the men's World Cup ended up returning to Mexico, to the bitterness of the United States.

This issue ends with a forgotten bid for the 1998 men's World Cup. Philippe Vonnard and Jérôme Berthoud reconsider one of the most surprising projects of the event's history, the Swiss bid of 1998, which had the particularity of not receiving a single vote in the FIFA executive committee! Vonnard and Berthoud attempt to analyse the reasons why Swiss football stakeholders developed a bid, even though the country could not objectively meet such an ambition either economically or politically and proposed an organization with stadiums that did not (or that do no longer) correspond to men's World Cup standards. Taking the opposite approach to studies that emphasize success stories surely brings new perspectives and ways of understanding.

The last three articles highlight the various aspects that explain the intriguing story of how a men's World Cup bid meets with success or failure. First, there are some national political aspects (political as well as economic stability, and support for the field of sports). In addition, the position of the country in the international football scene is important (a country involved in networking among international sports leaders or successful in football geopolitics). Moreover, these papers help us understand how the men's World Cup has progressively transformed into a mega-event and 
the implications this had in terms of hosting. Chile's 1962 edition and the Swiss 1998 failure clearly show the change in paradigm that occurred from the 1970s-1980s and ended up preventing countries with limited resources from hosting the event anymore.

The articles presented in this special issue explore new avenues of research on the history of the organizational aspects of the men's World Cup. However, it should be stressed that the field of exploration for historians interested in this domain is still vast. In its study of the men's World Cup history, this publication deliberately chose to limit itself to the twentieth century editions. The aim behind this choice was to focus on the rivalry between the two continents of football that dominated and characterized the tournament's early editions.

However, since the pioneering 2002 Korea/Japan edition, the men's World Cup has left its historic homelands. This move away from its dual epicentre is not an isolated phenomenon, as witnessed by the 2010 edition in South Africa and in the preparations of the 2022 edition in Qatar. While football had already reached a global scale in the last decades of the twentieth century, it is only in the twenty-first century that the event's organization itself has become more global. Recent studies of the competition have started to explore newer questions raised by this broadening of horizons. ${ }^{16}$ Similarly, the time frame chosen in this special issue limits the study to the male version of the competition, as its female counterpart appeared only at the end of the last century. The most recent edition of the women's tournament, hosted by France in 2019, makes it clear that this new aspect of the football World Cup is gaining in amplitude and calls on the social sciences to take up this as a serious subject of study. In the light of these major changes, the history of the World Cup will definitively have to combine the men's and women's tournaments in the near future, putting more emphasis on the latter.

\section{Notes}

1. Roche, Mega-events and modernity. For a recent discussion about this concept, see Müller, 'What makes an event a mega-event?'.

2. https://fr.fifa.com/worldcup/news/plus-de-la-moitie-de-la-planete-a-regarde-la-coupe-du-monde-2018.

3. Some authors have attempted to propose a chronology - mainly based on a Western European point of view on football's globalization. See notably: Giulianotti and Roberston, Globalization and Football; Bancel, Quin and Vonnard, 'Introduction: Studying the Europeanization of Football.'

4. Dietschy, Gastaut and Mourlane, Histoire politique des coupes du monde.

5. Brizzi and Sbetti, Storia della Coppa del Mondo di Calcio.

6. Helal and Cabo, Copas do Mundo.

7. Gonçalves Magalhães, Com a taça nas mãos. See also: Bolsmann, Marchi Júnior, Schausteck de Almeida and de Souza, 'Rationales, rhetoric and realities'.

8. Schiller, WM 1974; Simón Sanjurjo, España '82. See also: Guasco, Spagna '82; Dauncey and Hare, France and the 1998 World Cup.

9. For instance: Hughson, England and the 1966 World Cup; Porro, Martelli and Russo, Mondiale delle meraviglie. See also the two recent studies by Gillett and Tennent: 'Opportunities for all the Team' and "Filip" or flop?".

10. Wahl, Aspects de l'histoire de la coupe du monde.

11. Wahl, Histoire de la Coupe du monde.

12. Rinke and Schiller, The FIFA World Cup 1930-2010.

13. Wahl, Histoire de la Coupe du monde.

14. Gold and Gold, The Making of Olympic Cities; Girginov, Olympic Studies; Delaplace and Schut, Hosting the Olympic Games.

15. University of Paris 3, Institut des Hautes Études de l'Amérique latine (IHEAL), CREDA UMR 7227, University of Lausanne, Deutsche Sporthochschule-Cologne, De Monfort University-Leicester and the University of Limoges.

16. For instance, see: Bandyopadhyay, Naha and Mitra, 'FIFA World Cup and beyond'; Frawley and Adair, Managing the World cup. 


\section{Acknowledgments}

The authors want to thank Souvik Naha and Kausik Bandyopadhyay for their constant support during the process of compiling this volume. They are also grateful to the two experts that helped all the authors to improve the quality of their paper, and also to Shani D'Cruze, Claire Ferguson, Jennifer Gay and Eric Ausruhe for the proofreading of the papers. This special issue has received a financial support from the CREDA UMR7227 and from the Faculty of Social and Political Sciences of the University of Lausanne.

\section{Disclosure statement}

No potential conflict of interest is reported by the authors.

\section{Bibliography}

Bancel, N., G. Quin, and P. Vonnard. 'Introduction: Studying the Europeanization of Football in Historical Perspective.' In Building Europe with the Ball, eds. P. Vonnard, G. Quin, and N. Bancel, 1-17. Oxford: Peter Lang, 2016.

Bandyopadhyay, K., S. Naha and S. Mitra, eds. 'FIFA World Cup and Beyond: Sport, Culture, Media and Governance'. Sport in Society, 20, no. 5-6 (2017): 547-554. doi:10.1080/17430437.2016.1158475

Bolsmann, C., W. Marchi Júnior, B. Schausteck de Almeida, and J. de Souza. 'Rationales, Rhetoric and Realities: FIFA's World Cup in South Africa 2010 and Brazil 2014'. International Review for the Sociology of Sport 50, no. 3 (2014): 265-282.

Brizzi, R., and N. Sbetti. Storia della Coppa del Mondo di Calcio(1930-2018). Politica, sport, globalizzazione. Firenze: Le Monnier, 2018.

Dauncey, H., and G. Hare, eds. France and the 1998 World Cup: The National Impact of a World Sporting Event. Londres: Frank Cass, 1999.

Delaplace, M., and P.-O. Schut, eds. Hosting the Olympic Games: Uncertainty, Debates and Controversy. London: Routledge, 2019.

Dietschy, P., Y. Gastaut, and S. Mourlane. Histoire politique des coupes du monde de football. Paris: Vuibert, 2006.

Frawley, S., and D. Adair, eds. Managing the Football World Cup. Basingstoke: Palgrave Macmillan, 2014.

Gillett, A.G., and K.D. Tennent. "Filip" or Flop? Managing Public Relations and the Latin American Reaction to the 1966 FIFA World Cup'. Soccer \& Society 20, no. 7-8 (2019): 923-935. doi:10.1080/14660970.2019.1680493.

Girginov, V., ed. Olympics Studies. London: Routledge, 2015.

Giulianotti, R., and J. Roberston. Globalization and Football. London: Sage, 2009.

Gold, J.R., and M.M. Gold, eds. The Making of Olympic Cities. Critical Concepts in Urban Studies. London: Routledge, 2014.

Guasco, A. Spagna '82. Storia e mito di un mondiale di calcio. Roma: Carocci, 2016.

Helal, R., and D.C. Alvaro, eds. Copas Do Mundo. Comunicação eIdentidade Cultural no País do Futebol. Rio de Janeiro: Ed. UERJ, 2014.

Hughson, J. England and the 1966 World Cup. A Cultural History. Manchester: Manchester University Press, 2016.

Sugden, J., and A. Tomlinson, eds. Hosts and Champions: Soccer Cultures, National Identities and the USA World Cup. Aldershot: Arena, 1994.

Magalhães, G. Com a Taça Nas Mãos. Sociedade, Copa Do Mundo eDitadura no Brasil e na Argentina. Rio de Janeiro: Lamparina, 2014.

Müller, M. 'What Makes an Event a Mega-event? Definitions and Sizes'. Leisure Studies 34, no. 6 (2015): 627-642. doi:10.1080/02614367.2014.993333.

Porro, N., S. Martelli, and G. Russo, eds. Mondiale delle meraviglie. Calcio, media e società da 'Italia'90' a oggi. Milan: Franco Angeli, 2016.

Rinke, S., and K. Schiller, eds. The FIFA World Cup 1930-2010. Politics, Commerce, Spectacle and Identities. Göttingen: Wallstein, 2014.

Roche, M. Mega-events and Modernity: Olympics and Expos in the Growth of Global Culture. London, New York: Routledge, 2000.

Sanjurjo Simón, J. A. España '82: La Historia de nuestro mundial. Madrid: T\&B Editores, 2006.

Schiller, K. WM 1974: Als der Fussball modern. Berlin: Rotbuch Verlag, 2014.

Tennent, K.D., and A.G. Gillett. 'Opportunities for All the Team: Entrepreneurship and the 1966 and 1994 Soccer World Cups'. The International Journal of the History of Sport 35, no. 7-8 (2019): 767-788. doi:10.1080/ 09523367.2018.1544555. 
Tomlinson, A., and C. Young. National Identity and Global Sports Events: Culture, Politics and Spectacle in the Olympics and the Football World Cup. Albany: State University of New York Press, 2006.

Tumblety, J. 'La Coupe du monde de football de 1938 en France. Émergence du sport-spectacle et indifférence de l'État'. Vingtième Siècle. Revue d'histoire 93, no. 1 (2007): 139-149. doi:10.3917/ving.093.0139.

Wahl, A., ed. Aspects' de l'histoire de la Coupe Du Monde de Football. Metz: Université de Metz, 2007.

Wahl, A. Histoire de la Coupe du monde de football: Une mondialisation réussie. Brussels: P.I.E. Peter Lang, 2013. 